\title{
United Kingdom: Crisis Management and Bank Resolution Technical Note
}

This paper was prepared based on the information available at the time it was completed on July 11, 2011. The views expressed in this document are those of the staff team and do not necessarily reflect the views of the government of the United Kingdom or the Executive Board of the IMF.

The policy of publication of staff reports and other documents by the IMF allows for the deletion of market-sensitive information.

Copies of this report are available to the public from

International Monetary Fund • Publication Services

700 19th Street, N.W. • Washington, D.C. 20431

Telephone: (202) 623-7430 • Telefax: (202) 623-7201

E-mail: publications@imf.org •Internet: http://www.imf.org

\section{International Monetary Fund Washington, D.C.}


FINANCIAL SECTOR ASSESSMENT PROGRAM UPDATE UNITED KINGDOM

CRISIS MANAGEMENT AND BANK RESOLUTION TECHNICAL NOTE JULY 2011 
Glossary

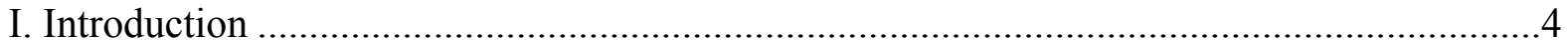

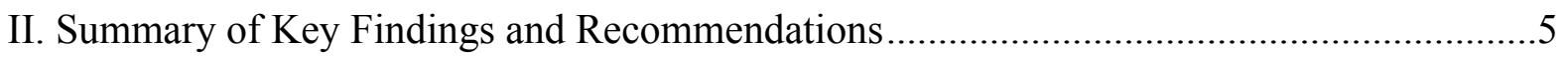

A. On Crisis Prevention and Early Intervention ..................................................

B. On the Special Resolution Regime and Resolution Tools ....................................5

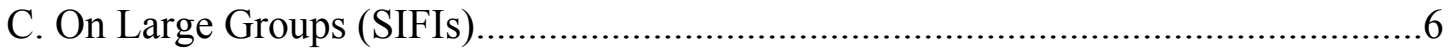

D. On the Need for International Harmonization .................................................. 7

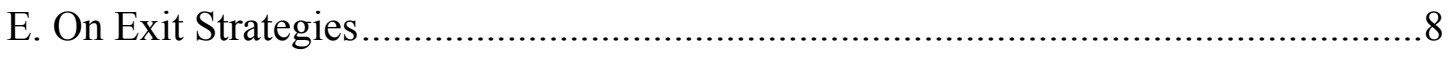

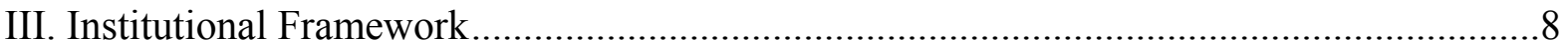

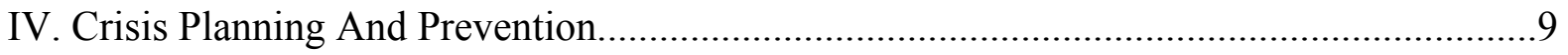

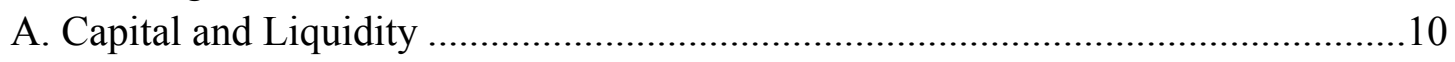

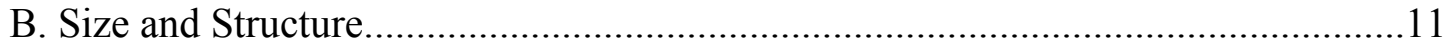

C. Cross-Border Issues................................................................................... 12

D. Recovery and Resolution Plans......................................................................... 13

V. Supervisory Action For Problem Banks ............................................................. 16

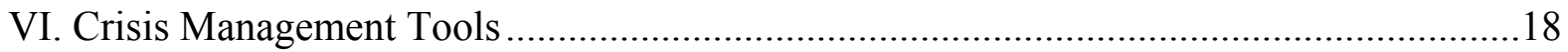

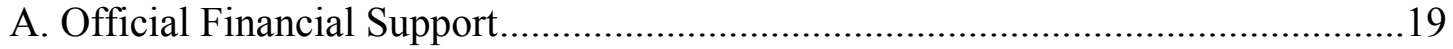

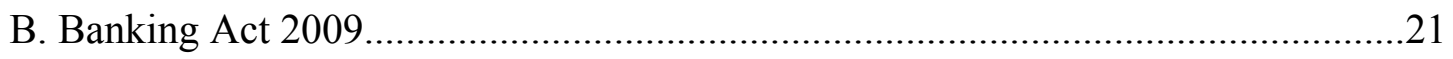

C. Financial Services Compensation Scheme......................................................... 31

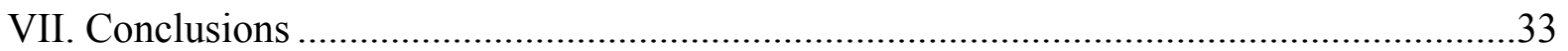

Boxes

1. Early Intervention Frameworks in Denmark and Canada........................................17

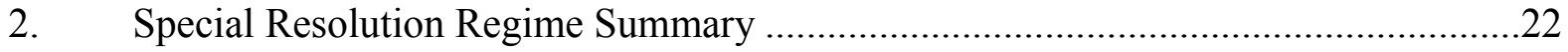

3. Investment Bank Insolvency and Client Assets ..............................................27 


\section{GLOSSARY}

$\begin{array}{ll}\text { APS } & \text { Asset protection scheme } \\ \text { BA } & \text { Banking Act 2009 } \\ \text { BIP } & \text { Bank insolvency procedure } \\ \text { BoE } & \text { Bank of England } \\ \text { BSPA } & \text { Banking (Special Provisions) Act 2008 } \\ \text { CASS } & \text { Client assets source book } \\ \text { CFCA } & \text { Critical Function Contingency Analysis } \\ \text { DWF } & \text { Discount window facility } \\ \text { ELA } & \text { Emergency liquidity assistance } \\ \text { EU } & \text { European Union } \\ \text { EWS } & \text { Early warning system } \\ \text { FPC } & \text { Financial Policy Committee } \\ \text { FSA } & \text { Financial Services Authority } \\ \text { FSAP } & \text { Financial Sector Assessment Program } \\ \text { FSB } & \text { Financial Stability Board } \\ \text { FSCS } & \text { Financial Services Compensation Scheme } \\ \text { HMT } & \text { Her Majesty's Treasury } \\ \text { IBC } & \text { Independent Banking Commission } \\ \text { LBIE } & \text { Lehman Brothers International Europe } \\ \text { LCFIs } & \text { Large and Complex Financial Institutions } \\ \text { MoU } & \text { Memorandum of understanding } \\ \text { OSFI } & \text { Office of the Superintendent of Financial Institutions } \\ \text { QFCs } & \text { Qualified financial contracts } \\ \text { RRP } & \text { Recovery and Resolution Plan } \\ \text { SARs } & \text { Special administration regulations } \\ \text { SIFIs } & \text { Systemically Important Financial Institutions } \\ \text { SLS } & \text { Special liquidity scheme } \\ \text { SRR } & \text { Special Resolution Regime } \\ \text { TPO } & \text { Temporary Public Ownership } \\ \text { U.K. } & \text { United Kingdom } \\ \text { U.S. } & \text { United States } \\ & \end{array}$




\section{INTRODUCTION ${ }^{1}$}

1. The United Kingdom was badly hit by the global financial crisis starting in 2007. Since London is a major global financial center, the U.K. market is closely interconnected with institutions, markets, and activities in other parts of the world and was thereby affected by developments elsewhere. In addition, there were severe domestic imbalances, such as high leverage in lending to the real estate sector and a developing price bubble in real estate.

\section{The U.K. authorities responded to the crisis through a number of measures;} many of them similar to those executed in other countries. Indeed, some measures were decided and harmonized through European Union (EU)-wide agreements in order to ensure level playing field conditions. In other respects however, some aspects of the crisis response in the United Kingdom (and in other EU countries) revealed fault lines in the EU's integrated market for financial services, particularly as regards cooperation amongst member states in resolution.

3. In having to manage a systemic crisis, the U.K. authorities found themselves lacking either effective instruments or an adequate legal framework for various types of intervention. Formal arrangements were in place for cooperation and information-sharing between the authorities, but those had not been tested before under severe stress. As a result, of gaps in the crisis management framework, the authorities had first to resort to ad hoc solutions; sometimes finding that those tended to be less orderly and, hence, more disruptive and expensive.

4. As the crisis progressed, the authorities used their experiences to strengthen the crisis management framework. In this respect, introducing a permanent law for bank ${ }^{2}$ resolution was a key piece. The new legislation on bank resolution provides increased certainty to bank stakeholders, as well as to the authorities, and should thus improve the prospect of retaining or restoring confidence in the financial system, which is the main objective in a crisis.

5. This technical note discusses the current framework for crisis management in the United Kingdom. Crisis management includes the preparations, the organization and the tools for the authorities' management of a crisis. This note is structured as follows: Chapter II summarizes our key findings and recommendations; Chapter III analyses the institutional framework for crisis management and bank resolution; Chapter IV assesses crisis prevention measures, including the approaches to identify and deal with potential problem institutions at an early stage; Chapter V covers the competent authorities' early intervention and preresolution enforcement powers; and Chapter VI examines the crisis management tools

\footnotetext{
${ }^{1}$ Prepared by Göran Lind (Sveriges Riksbank and IMF external consultant) and Sean Kerr (IMF/LEG).

${ }^{2}$ In many instances in this note the word "bank" will cover commercial banks as well as building societies.
} 
available to the U.K. authorities, focusing in particular on official financial support (both emergency liquidity assistance and solvency support), the Special Resolution Regime (SRR) under the Banking Act 2009 (BA) and deposit insurance under the Financial Services Compensation Scheme (FSCS). Chapter VII contains our concluding remarks. Throughout the note, the focus of the analysis is to assess to what extent the framework will contribute to improving financial stability, in particular in a crisis.

\section{SUMMARY OF KEY FINDINGS AND RECOMMENDATIONS}

\section{A. On Crisis Prevention and Early Intervention}

6. The IMF mission supports the enhanced role for macro prudential oversight. In order to avoid unreasonable expectations, it is critical that the mandate is transparent but also limited to what the Financial Policy Committee (FPC) can realistically deliver. The FPC must also be provided with the appropriate tools to take necessary measures to achieve its objectives. It will be important to align the roles of macro and micro supervision not only to avoid gaps but also to avoid duplication of tasks. Finally, certain governance issues must be addressed, e.g., by taking measures to strike an appropriate balance between the objectives of monetary policy and macro prudential oversight.

7. The IMF mission strongly supports the more forward-looking approach adopted by the authorities since the onset of the crisis, exemplified through the use of stress tests across a wide range of deposit-taking institutions to identify potential problem institutions at an early stage, and to share this information with other relevant authorities. $^{3}$ The mission encourages the Financial Services Authority's (FSA) plans to introduce a step-wise approach based on indicators in order to take early supervisory action. It is also important that the approaches to identify and address problems at an early stage, and to involve other authorities, are embedded in the normal processes of the FSA and, as relevant, in the processes of the Bank of England (BoE), the FSCS, and Her Majesty's Treasury (HMT). The FSA needs to have a wide range of supervisory tools at its disposal and to have clear legal powers and, indeed, obligations to act flexibly, adequately, and in a timely manner to mitigate weaknesses in banks before they have manifested themselves. The FSA must also have adequate means and processes to effectively monitor that its orders are implemented by the affected institutions.

\section{B. On the Special Resolution Regime and Resolution Tools}

8. The mission encourages the authorities to consider expansion of the SRR (and, if necessary, its amendment and adaptation) to establish resolution tools for other potentially systemically important firms, such as investment banks, insurance firms,

\footnotetext{
${ }^{3}$ See further discussions on this issue in the report on the assessment of U.K.'s compliance with the Basel Core Principles for Effective Banking Supervision (IMF, July 2011), notably Core Principle 23.
} 
and payments system infrastructure providers. While the present modalities of the SRR may not fit such firms exactly, certain features of the SRR (particularly the private sector transfer arrangements) could be useful in the resolution of other types of firms.

9. The mission agrees that it might be beneficial to extend the power to temporarily suspend contractual termination clauses for a short period of time at the initiation of a resolution, pending a possible transfer of such contracts, to derivatives and other financial contracts. If contracts are transferred to a solvent transferee, enforcement of early termination rights should not be available unless and until the transferee itself defaults. If not, termination rights should be enforceable. The mission understands that this specific issue will require the amendment of European legislation and that the issue is on the European Commission's current agenda. ${ }^{4}$

\section{On Large Groups (SIFIs)}

10. The mission considers that the SRR is a useful framework for dealing with small- and medium-sized deposit-taking institutions and constitutes a significant step forward for the U.K.'s bank resolution and crisis management framework. However, the operational, legal and political challenges in dealing with a large banking group will limit the practical use of the SRR as constituted at present, not least given that its provisions do not have extraterritorial effect. Hence, the mission supports the present discussions in the United Kingdom, which are aiming at finding enhanced solutions for large banks, designed to improve the resolvability of those banks. Such solutions may include:

- $\quad$ Stricter regulations. The mission supports the present stricter regimes for bank capital and liquidity used as a supervisory tool by the FSA. The IMF understands that the U.K. authorities promote current international negotiations aiming at harmonizing stricter rules, e.g., on capital, for Systemically Important Financial Institutions (SIFIs);

- $\quad$ Contingent capital (CoCos) and bail-in capital. In this area, the way forward must go through international agreements and the mission understands that the U.K. authorities take an active role in promoting such agreements;

- $\quad$ Recovery and resolution plans. The IMF mission encourages the progress that has been achieved so far. An important step is now to move from collecting information

\footnotetext{
${ }^{4}$ The desirability (or otherwise) of suspending close-out netting raises a number of complex issues, particularly in light of regulatory moves to require increased central clearing of standardized derivatives contracts. Part of the European Commission's consultation on the brief, temporary suspension of close out netting considers whether or not certain classes of counterparty (central banks, central counter parties (CCPs), payment and securities settlement systems and others that avail of the protections afforded by the Settlement Finality Directive) ought to be excluded from any suspension.
} 
to presenting (by the banks and by the authorities, as appropriate) approaches that will increase the resilience of banks and make them easier to resolve. A related and equally important step is to achieve agreement on recovery and resolution plans, and their implementation between home and host authorities for international groups.

- $\quad$ Protecting depositors. The mission concurs with the aim to protect key economic functions, such as providing current deposits and payment services, but is flexible on the means to achieve this. While the IMF expresses no view on the merits of depositor preference and acknowledges that countries have chosen different options on this issue, we understand that the issue of depositor preference may be revisited in the present broad debate in the United Kingdom on dealing with large institutions that perform depositor-oriented activities as well as others. ${ }^{5}$

\section{On the Need for International Harmonization}

\section{The mission is fully cognizant of the fact that the U.K. authorities' ability to take} unilateral action on regulatory reforms is limited in practice. The benefit of harmonized EU legislation and globally agreed reforms inevitably limits scope for unilateral action. Moreover, the extensive integration of financial markets and groups makes nationally introduced measures less effective. Thus, we encourage the U.K. authorities in their efforts to contribute to international solutions on a number of important issues, notably:

- $\quad$ On SIFIs (as noted above); and

- On cross-border resolution. For example by finding ways to avoid unilateral action such as geographical/territorial ring-fencing at the point of resolution, which may lead to less-than-optimal overall solutions. It might be possible to use the supervisory colleges or the cross-border crisis management groups to reach compromises between home and host authorities. For instance, increased insight and influence by host authorities could be offered by home authorities in exchange for commitments on joint solutions as part of bilateral/multilateral resolution agreements, including principles for burden sharing, in a crisis situation. ${ }^{6}$ Ultimately, the difference between jurisdictions in their international insolvency regimes must be solved in order to facilitate cross-border resolution.

\footnotetext{
${ }^{5}$ The April 2011 Interim Report of the Independent Commission on Banking discusses depositor preference noting how subordinating the claims of other unsecured creditors to those of depositors creates a larger buffer for the absorption of losses, facilitating resolution, particularly where there is a political imperative to avoid losses for retail depositors.

${ }^{6}$ Scope for compromises within supervisory colleges may be constrained by applicable legal frameworks. For example, if a jurisdiction has a ring-fencing law for branches of foreign banks, its resolution authority would likely be unable to agree to transfer assets of the branch to the home jurisdiction for distribution by the home jurisdiction authorities in a bank resolution proceeding.
} 
- $\quad$ On deposit guarantee schemes. The mission finds the present deposit guarantee arrangements in the United Kingdom to be flexible and hence useful for resolving crisis situations not only through direct payout but also via contributions to resolution transactions. Also, for deposit guarantee schemes, internationally harmonized rules are key and the U.K. authorities are actively participating in current discussions in the EU on amending the current EU Directive. The mission notes that the U.K. scheme is post-funded. Countries in the EU, and globally, follow different approaches to funding. One of the issues to be discussed in the EU in the near future is whether countries can agree on a common approach to this issue.

\section{E. On Exit Strategies}

12. The IMF mission encourages the U.K. authorities to continue their efforts to dismantle the crisis' special measures in an orderly manner, thereby promoting the return of all normal functions to the financial markets. The mission supports the approach of encouraging institutions to reduce their reliance on support measures, if possible, earlier than formally agreed. This would reduce the risk of market pressures, or perceived market pressures, resulting from "humps" of expected repayments at certain points in time. Early repayment would also increase market confidence as to the recovery of the affected institutions.

\section{INSTITUTIONAL FRAMEWORK}

\section{The current institutional arrangements regarding crisis management are} broadly appropriate. The financial stability responsibilities of the different authorities are set out in a memorandum of understanding (MoU) between the BoE, FSA, and HMT.

14. While the regulatory architecture in the United Kingdom is subject to imminent and rather dramatic change by HMT, the Financial Sector Assessment Program (FSAP) is nevertheless a 'point in time' exercise and, as such, the authorities' crisis management responsibilities under the current $\mathrm{MoU}$ are summarized below. Since the introduction of the BA however, some of these responsibilities are now placed on a statutory footing. Notably, the BoE is now subject to a statutory objective to contribute to protecting and enhancing the stability of the U.K. financial system while its payment system oversight function has also been placed on a statutory footing. Similarly, while the MoU remains important, the Banking Act now formalizes the roles and responsibilities of the various authorities for bank resolution in more concrete terms than under the MoU. It will be noted that the FSCS is not a party to the MoU though it is clearly a key component of the crisis management framework. The FSCS has a MoU with the FSA and a protocol with the BoE. The FSCS' role and responsibilities are detailed in paragraphs 71 to 77 below.

- HMT: in addition to the overall institutional structure of financial regulation and the legislation that governs it, informs and accounts to parliament regarding the 
management of serious disruptions to the financial system and measures to resolve them (including exceptional solvency support from HMT itself);

- $\quad$ The BoE: acts as lender of last resort in order to limit risk of problems affecting a particular institution from spreading to other parts of the system. Oversees payment systems. Acts as the lead resolution authority for failing U.K. banks and building societies under the special resolution regime introduced by the BA.

- $\quad$ FSA: prudential supervisor. Key operational role is for example, resolving problems at firms prior to resolution via capital raising; and business disposals. Triggers the SRR and is responsible for authorization and supervision of bridge banks created under the SRR.

15. Cooperation and information sharing among the responsible authorities is key to successful crisis management. The MoU among the tripartite authorities emphasizes the requirement for the free flow of information between them. As far as the mission could discern, interaction amongst the authorities has increased since the beginning of the crisis, both in its frequency at different organizational levels and by involving other authorities at earlier stages. For instance, the FSA has conducted stress-tests on a range of institutions with the aim of identifying outlier institutions that may be vulnerable. The tripartite authorities in joint working groups have then monitored the development of the identified potential problem institutions and have discussed preventative measures aimed at maintaining financial stability. Early dialogue amongst the authorities should help banks to improve the chances of institutions being stabilized before the threshold conditions have been breached or special resolution required.

\section{Crisis Planning And Prevention}

\section{The United Kingdom is embracing a range of crisis planning and prevention} initiatives that will be of utmost importance as regards larger, more complex banking groups. The SRR and, indeed, the normal crisis management framework in general, seem best equipped to handle small- and medium-sized, standalone deposit-taking institutions. As far as larger, more complex cross-border banking groups are concerned, there is greater execution risk and complexity involved in applying the SRR tools while achieving an orderly resolution (apart from temporary public ownership (TPO)). This has not so much to do with any weaknesses in the SRR but simply the less 'resolvable' nature of the large and complex financial groups, and the fact that the SRR powers cannot automatically be applied extra-territorially. In order to avoid expensive alternative solutions, such as the government recapitalizing a bank as a going concern, the way forward would likely include those proposed by the U.K. authorities to increase the resilience of the banks and to make them more resolvable. To this end, the authorities are pursuing a range of supplementary and mutually reinforcing approaches, such as: 
- Methods to strengthen the resilience of a bank in normal times, such as tougher capital and liquidity requirements for large banks. The United Kingdom made an early start in developing such rules and is now working within international bodies such as the Financial Stability Board (FSB) and the Basel Committee to reach agreements on international standards.

- $\quad$ Methods to ensure that the private stakeholders contribute to stabilize a weak bank before the institution ceases to be viable. This is exemplified in the current international regulatory debate regarding measures to increase banks' loss absorbency, whether through new types of contingent capital instrument, with contractual triggers (so-called 'co-cos') or through statutory 'bail-in' powers tied to resolution.

- $\quad$ Methods to simplify the legal and operational structure of large and complex banks. This will make it easier to isolate and resolve the core components of a bank, as seen from a public interest perspective, should a crisis occur. The FSA, supported in degree by the BoE, are in the process of making all large banks present recovery and resolution plans (RRPs) for this purpose (see paragraphs 29 to 34 for further discussion). Among other things, the plans will outline the bank's preparations for various contingencies, such as sudden needs for capital and liquidity, and also identify how group entities and activities may be split off and sold without endangering the systemically important functions performed by the bank. When necessary, the FSA will recommend a bank already in a normal situation to take steps to reach a simpler structure that is easier to manage, supervise and resolve.

- $\quad$ Methods to improve macro-prudential oversight.

17. The IMF mission concurs with the approach taken by the U.K. authorities and recognizes that the international debate in these areas is still evolving. The consequences of failures in large groups are potentially of a much greater magnitude and the groups are not easily resolvable through the ordinary methods. Stricter regulatory and supervisory requirements constitute a necessary first line of defense. This is also an appropriate approach from the point of view of maintaining a level playing field, since the costs of capital and funding are generally lower for SIFIs, due to the implicit assumption of their being too big to fail, and thus having a perceived guarantee of being rescued by the authorities.

\section{A. Capital and Liquidity}

\section{Since 2009, the FSA applies an enhanced regime for bank capital and bank}

liquidity. The supervisory framework for bank capital is known as " $4 / 6 / 8$ ". The numbers imply: 
- In the outcome of a stress test based on FSA-generated parameters, the bank's common equity capital should not drop below 4 percent during the coming ' $x$ ' years.

- The bank's common equity capital should remain at or above 6 percent on a continuous basis also in nonstressed situations.

- $\quad$ The bank's tier 1 (core) capital, including common equity but also other accepted instruments, such as certain forms of hybrid capital, should at all times be at or above 8 percent.

19. On liquidity, the FSA conducts intensified monitoring according to quantitative as well as qualitative rules.

20. The enhanced regime is primarily aimed at banks that received some form of public support during the crisis. The IMF mission concurs with the enhanced measures, which will assist the authorities in identifying weak banks at an early stage, thus facilitating the taking of remedial action.

21. Challenges remain as regard to the terms and modalities of both contingent capital instruments designed to improve (via contract) a firm's pre-resolution resilience, and as regard to the possible scope of statutory bail-in powers, which may further increase loss absorbency in a resolution. In particular, there are reasonable questions to be asked concerning investor appetite for instruments susceptible to contractual or statutory conversion or write down. Further, there is not yet any international agreement on giving regulators "bail-in" powers as a resolution tool. Nevertheless, there seems to be broad global acceptance at least among policymakers that this approach should be explored further and the United Kingdom is actively involved in the international debate. ${ }^{7}$

22. The vulnerabilities of the SIFIs is a global issue, although the U.K. market is heavily affected, since it is the home country for several domestic SIFIs as well as hosting entities in many SIFIs domiciled abroad. The ultimate solution to the SIFI challenges must be reached through global agreements and harmonization.

\section{B. Size and Structure}

23. Both the stricter regulatory requirements and the use of bail-in powers, if adopted could reduce the risk of disorderly failures in SIFIs. Simplifying the legal and operational structures of SIFIs, if done in normal times, could also reduce the risk of failures,

\footnotetext{
${ }^{7}$ See IMF Staff Discussion Note "Contingent Capital: Economic Rationale and Design Features" January 25, $2011 \mathrm{http}: / /$ www.imf.org/external/pubs/ft/sdn/2011/sdn1101.pdf See also IMF Staff Discussion Note“"'Bailins" a Statutory Approach to Bank Debt Restructuring" (forthcoming).
} 
e.g., through reducing intra-group connections, and simplifying resolution to enable more orderly winding down.

\section{There is currently a vivid debate on the topic of the large bank issues in the}

United Kingdom. The Independent Banking Commission (IBC) is analyzing broad issues related the size and structure of U.K. banks. While the IBC's final report is not expected until later this year, public pronouncements to date have hinted at the possibility of drawing some kind of dividing lines. ${ }^{8}$ This feeds into the question of the appropriateness of "subsidiarization" as a means of separating a bank's depositor-related functions and its seemingly more "risky" investment operations. ${ }^{9}$ From the discussions between the mission and the U.K. authorities so far, it seems that while there is general agreement that mixing protected and other activities in a financial institution poses challenges, no preferred approaches to deal with the matter have yet been identified. Further, it will be important to see how the findings of the IBC move the debate forward later in the year.

\section{Cross-Border Issues}

\section{As a major financial center, the United Kingdom is both a home and a host} country to banks. As a member of the EU, the United Kingdom must apply the so called Passport Rules, which allow a bank established elsewhere in the EU to open branches in the United Kingdom, which are regulated and supervised by the home country supervisor. The EU rules do not allow a host country to force EU-domiciled banks to change their presence from branch status to subsidiary status. If subsidiaries are opened, these will be domiciled and authorized in the United Kingdom and, in those cases, the U.K. supervisors will become the home authority. The Passport Rules are intended to promote financial integration in Europe.

26. Problems in a U.K. branch of a foreign bank could, under certain circumstances, have negative implications for financial stability in the overall system or important parts thereof. Even if the branch has a limited market share it could destabilize the market, e.g., by affecting depositors' and other counterparties' confidence in the system. Against this background, many mainly "host countries," including the U.K., have pushed to be allowed stronger tools to supervise and, if necessary, to take steps to protect themselves from potential problems of the branch. According to current EU legislation, the host country may

\footnotetext{
${ }^{8}$ An interim report was published on 11th April, 2011. Among other things it proposes mandatory subsidiarization of the retail activities of a bank, allowing but limiting the exposures between the retail subsidiaries and other parts of the bank. The retail subsidiaries should maintain a core capital ratio (CET1) of at least 10 percent provided there is an increased loss absorbency of debt through the use of CoCos or bail-in instruments (if not the CET1 capital should be even higher).

${ }^{9}$ Cross-Border Banking Groups as Subsidiaries or Branches: Does One Size Fit All? (IMF, forthcoming)
} 
regulate the liquidity of the branch, but not anything else. ${ }^{10}$ To that end, the U.K. authorities place increased importance on obtaining frequent whole-firm liquidity information in respect of banks for which they are the host supervisor, in order to make their own risk assessments.

\section{As a first step, the U.K. authorities would seek to achieve progress through} multilateral approaches, such as closer coordination and information sharing between home and host authorities, for instance by using the supervisory colleges established for all significant groups. This should also lead to better opportunities to, when needed, influence decisions that affect a bank branch. That said, the U.K. authorities believe that there needs to be a better balance between the home and host supervisors, so as to make decisions to protect the branch.

28. The IMF mission acknowledges the seriousness of the issue, as evidenced by the effects on the U.K. financial market from the failures of Lehman Brothers and the Icelandic banks. Like the U.K. authorities, we believe that a solution must be sought through internationally harmonized agreements. The main incentive could be the parties' mutual interest in collaboration. Host authorities need more information and more influence whereas the consolidating supervisor needs commitments from the host authorities on crisis management; for example, against the taking of unilateral action.

\section{Recovery and Resolution Plans}

\section{The Financial Services Act 2010 requires the FSA to make rules for the} preparation and presentation by banks of RRPs. The aim of a recovery plan is to compel the leadership of an institution to, in normal times, make contingency plans for how the various stresses can be mitigated, e.g., by raising capital and liquidity. Firms are also required to provide resolution analysis and information to explain how the institution's key or systemically significant economic functions are distributed across the organization. Ultimately, the aim is for the bank to explain which economic functions in the institution are systemically important and how they could be separated in the event of failure. The authorities then develop institution specific resolution plans based on that material. By so doing, the resolution of large and complex financial institutions (LCFIs) also might be facilitated. This is hoped to be one of the approaches to mitigate the problem of some firms being "too big to fail but at the same time too big to rescue". ${ }^{11}$ Primary responsibility for the 'recovery' element of the plan rests with the firm itself. To the extent that a recovery plan proves unable to turn the fortunes of an ailing firm, resort would be had to the 'resolution' plan, for which the regulator is primarily responsible.

\footnotetext{
${ }^{10}$ Changes to the Capital Requirements Directive may yet limit host countries' ability to regulate liquidity locally.

${ }^{11}$ See "Cross-Cutting Themes in Economies with Large Banking Systems"; IMF Policy Paper; April 16, 2010 http://www.imf.org/external/np/pp/eng/2010/041610.pdf.
} 
30. While there is no regulation as yet on the modalities and content of an RRP, an important pilot project is at an advanced stage. The FSA and the BoE have produced detailed draft templates for RRPs. These are currently being used in a pilot study covering six major U.K. bank groups. The template has a five module structure:

- $\quad$ The Overview. This part is, inter alia, intended to ensure that the RRP is agreed and understood by the Board and senior management of the bank and that it is integrated into the bank's risk management approach.

- $\quad$ The Recovery Plan. This part invites the bank to select some 5 to 10 options; for example, contingency plans, for addressing extreme financial stress impacting the bank. The recovery plan will identify various events, both firm-specific and large system failures. For each event, the plan will outline how the range of options may be used by the bank to deal with the ensuing challenges. Although the bank may freely select its options, the template prescribes that the plan must include options for recovering from or avoiding capital and liquidity difficulties (since these are seen as the most likely and the most critical to the bank).

- $\quad$ Group Structure and Key Legal Entity Information. This module is aimed at understanding how and where in the group significant economic functions of the institution are performed and to what extent the functions are also dependent on other legal entities. Additionally, the module describes major financial intra-group interdependencies.

- U.K. Economic Function Identification Matrix. The matrix provides an overview of the main economic functions performed by the institution in the U.K. market (such a function may also be produced from a group entity located in a different jurisdiction). The aim of the matrix is to single out those economic functions that are significant to the financial stability in the United Kingdom.

- U.K. Critical Function Contingency Analysis (CFCA). Each critical economic function in the United Kingdom, as identified under the previous module, will have a CFCA. The CFCA will analyze in which ways a particular economic function may be separated from other parts of the group, while preserving the continuity of the function (or winding it up in an orderly fashion). Such separation will facilitate the use of the resolution tools, when and if necessary.

31. The IMF mission welcomes the efforts in trying to make the concept of recovery and resolution plans more concrete and operational. The present pilot study is the second in a short period and the banks and the authorities conduct an iterative process using the experiences to further refine the processes and the template. The process of filling in and assessing an RRP for a large group involves a large amount of work for both the bank and the authorities, not least because these are, to some extent, uncharted waters where data and 
other information must be collected and analyzed in new ways. The RRP implies looking at structures and operations differently from the types of analysis that have been performed in the past.

\section{With that said, there should be some caution against having too high}

expectations of RRPs. There are many circumstances that could limit their usefulness in a crisis, in particular if systemic. This may reduce the capacity of individual firms to generate the levels of capital and liquidity they had envisioned in an idiosyncratic firm crisis. For example: the causes of the crisis may differ from those planned for; contingency arrangements may not work as planned (such as committed liquidity lines not being available due to broad market disturbances; or there may temporarily be a lack of interested purchasers for the bank's businesses or entities).

\section{Even while acknowledging these challenges, the mission finds the RRP exercise} very useful for several reasons. First, it forces the bank's leadership to collect, structure, and analyze information in new ways. This form of introspective analysis could lead management to question why functions are organized in the group in the ways that they are. In the best of cases, this could lead to voluntary changes by the bank, simplifying its operations. Secondly, the relevant authorities may require a firm to make structural and organizational changes if RRP discussions suggest that the firm - in its existing shape - is not easily resolvable. The overall RRP exercise should be useful also for improving the ordinary regulatory and supervisory work. Finally, the mission appreciates the approach (the fourth module) to identify the systemically critical economic functions of individual banks. This is done irrespective of how these functions are performed within and spread across the group. By focusing on functions rather than on structural and legal entity organization, the authorities may be able more easily to take resolution measures (or gain an understanding of possible structural changes that could improve resolvability) as well as other steps to protect the key components that make a specific bank systemically important.

\section{The FSB is presently developing internationally consistent RRPs for the use of} internationally active financial groups. Although the U.K. authorities have developed their own template for the pilot studies, they aim at harmonizing and integrating them into the developing international standard. In particular, it is important that information pertaining to RRPs is shared between home and host members of the cross-border crisis management groups, which are being established for all major international financial groups. Specifically, the host authority would have a strong interest in obtaining more information about entities and economic functions where the sudden withdrawal would represent systemic risks in that jurisdiction. Such information sharing must be performed subject to strict secrecy requirements, since the information is highly sensitive, e.g., competitors may benefit from knowing in detail about a bank's structures and interdependencies. 


\section{Supervisory Action For Problem Banks}

35. Effective crisis management hinges on the authorities identifying and addressing bank problems at an early stage. Previously, however, as reported by independent committees commissioned to assess the authorities' work in crisis situations, the FSA had a tendency to postpone taking formal remedial action, instead trying to correct problems by persuading bank management to take voluntary action. While such an approach constitutes an appropriate first step, it should be followed by formal requirements for action if satisfactory rectification of the problem is not obtained in the short term. Formal requirements must also be monitored by requesting the relevant bank to provide frequent progress reports.

36. The processes to enable early identification of problems have been strengthened, for instance by introducing across-the-board stress tests in order to identify vulnerable outlier institutions. In addition, the FSA is planning to introduce an indicator-based early warning system (EWS), which would signal the need to take early action to mitigate increasing vulnerabilities in individual banks. The system is not expected to be fully automatic or nondiscretionary. It will not be based just on quantitative indicators, such as bank capital, but will leave room for the supervisor's judgment. By way of international comparison, the early intervention frameworks of Canada and Denmark are detailed in the text box below. It should be noted that the Canadian framework includes triggers for contacts and information sharing between the involved authorities.

37. Under the 'own initiative variation of permission power' contained in the Financial Services and Markets Act, the FSA has a broad range of remedial measures at its disposal. The FSA can use its variation of permission powers in order to mitigate emerging problems in banks, including the powers to temporarily stop the paying of dividends, to request the postponement of taking up new activities, or to terminate existing activities. Ultimately, the FSA may revoke a bank's license if it finds that the bank no longer meets the conditions required for it to be licensed.

38. The FSA regularly uses the discretionary capital requirements under Pillar 2 (within the Basel II framework) to require individual banks to hold additional capital in certain circumstances when the bank's risks are deemed to be higher than its peers, for instance based on the result of stress tests. 


\section{Box 1. Early Intervention Frameworks in Denmark and Canada}

\section{Denmark (The Diamond framework)}

The Danish framework consists of five quantitative indicators. Until end-2012, when the rules will enter into force, the supervisory authority will monitor to ensure that banks are moving toward the established limits. Starting in 2013, the supervisor will take remedial action in cases where the limits are breached. The five indicators are:

- The aggregate sum of all large exposures (a large exposure is defined as the sum of exposures to a client or to a group of connected clients, if it exceeds 10 percent of the bank's core capital) must not exceed 125 percent of the bank's core capital.

- The bank's lending growth must not exceed 20 percent per year.

- The amount of lending for real estate (commercial property) purposes must not exceed 25 percent of total lending.

- The bank's funding ratio is defined as aggregate lending divided by working capital (all shares, junior and senior debt, but excluding debt shorter than one year). The funding ratio must not exceed 1 .

- Liquidity coverage, defined as retail deposits in relation to wholesale funding must be at least 50 percent.

In addition, the recently agreed Basel III standards will apply and will be introduced according to the time schedule to be established in the relevant EU legislation, i.e., the LCR and NSFR, for liquidity and funding.

\section{Canada}

The Canadian framework (issued by the Office of the Superintendent of Financial Institutions (OSFI)) consists of four stages (in addition to the "all normal" stage). Each stage is identified by a set of conditions and a number of options for supervisory measures. The framework also includes guidelines for the interaction between the authorities, including the Canada Deposit Insurance Corporation (CDIC).

- Stage 1 Early Warning. The conditions are (i) The combination of the institution's overall net risk and its capital and earnings compromises the institution's resilience; and (ii) the institution has issues in its risk management or has control deficiencies that, although not serious enough to present a threat to financial viability or solvency, could deteriorate into more serious problems if not addressed.

- $\quad$ The supervisory measures at stage 1 include meeting the bank's management, conducting more frequent and intrusive on-site supervision, and requiring additional and more frequent reporting.

- At stage 1, the OSFI informs the CDIC that the institution is in the staging framework, and about any action the OSFI intends to take. The OSFI will send intervention reports to the CDIC and they will hold joint meetings to discuss the risk profile of the institution. The FISC or sub-FISC will be updated.

- Stage 2 Risk to financial viability or solvency. The conditions are (i) the combination of the institution's overall net risk, capital and earnings makes it vulnerable to adverse business and economic conditions which may pose a serious threat to its financial viability or solvency, unless effective corrective action is implemented; and (ii) the institution has issues in its risk management that, although not serious enough to present an immediate threat to financial stability or solvency, could deteriorate into more serious problems if not addressed.

- $\quad$ The supervisory measures at stage 2 include requiring the institution to rectify problems within a specified timeframe, requiring the institution's external auditor (or another auditor, appointed by the OSFI) to extend the scope of the review of the financial statements or to conduct other procedures as specified by the OSFI, or developing a contingency plan to enable the OSFI to take rapid control of the assets of the institution in case of rapid deterioration. 


\section{Box 1. Early Intervention Frameworks in Denmark and Canada (concluded)}

- At stage 2, the OSFI will inform the CDIC of results and data obtained from enhanced supervisory reviews, expanded audits, and enhanced monitoring. The OSFI and CDIC will commence contingency planning.

- Stage 3 Future financial stability in serious doubt. The conditions are (i) the combination of the institution's overall net risk, capital, and earnings makes it vulnerable to adverse business and economic conditions, which pose a serious threat to its financial viability or solvency, unless corrective action is promptly taken; and (ii) the institution has significant issues in risk management or control deficiencies, which present a serious threat to its financial viability or solvency, unless effective corrective action is promptly implemented.

- The supervisory interventions at stage 3 include directing specialists to assess specific areas such as the quality of loan security, asset values, and sufficiency of reserves; enhancing the scope of business restrictions put on the institution; sending OSFI staff to the institution to monitor the situation on an ongoing basis; expanding contingency planning; and communicating to the management the importance of considering resolution options, including seeking a prospective purchaser.

- At stage 3, there will be regular meetings in the sub-FISC and the FISC to discuss the evolving situation and contingency planning. The CDIC and the OSFI will discuss the situation of the institution in depth.

- Stage 4 Nonviability/insolvency imminent. The conditions include (i) the institution has failed to meet regulatory capital requirements in conjunction with an inability to rectify the situation on an immediate basis; (ii) the statutory conditions for taking control have been met; and (iii) the institution has failed to develop and implement an acceptable business plan, resulting in either of the two preceding circumstances becoming inevitable within a short period of time. At stage 4, OSFI has determined that the financial institution will become nonviable on an immediate basis.

- At stage 4 regular inter-agency (FISC) meetings shall be held, focusing on coordinated implementation of intervention measures.

- The OSFI activities at stage 4 may involve: Assuming temporary control of the assets (provided that the statutory conditions exist); Taking control of the assets (provided that the statutory conditions exist); Requesting that the Attorney General apply for a winding-up order.

\section{Crisis Management Tools}

\section{In developing crisis management tools, the U.K. authorities learned lessons from} their experience during the recent, severe crisis. Probably the most important lesson was the need to have in place a legal framework for the resolution of banks (i.e., a special resolution regime). Lacking such a framework at the time of the Northern Rock crisis in 2007 made crisis management in itself more difficult, but, more importantly, it led to uncertainties in the markets which undermined credibility and aggravated the crisis.

40. The characteristics of a crisis can always differ from earlier crises, so authorities need to be prepared to apply flexibility rather than working from a set framework. This is a conclusion that all countries have drawn from the crisis. Following a more flexible approach in this crisis, the BoE (and their central bank counterparts globally) provided 
liquidity to banks on more flexible terms than traditionally, while HMT recapitalized banks and also provided solvency support through guarantees of assets and liabilities.

\section{A. Official Financial Support}

\section{Banking sector liquidity support}

41. During the crisis, liquidity support was provided by the BoE through newly created facilities outside the normal repo facility. A greater amount of liquidity was also provided on longer terms (up to one year) than in its normal pre-crisis operations, and against a wider range of collateral. Liquidity was also provided in foreign currency, notably U.S. dollars (while some U.K. banks also had direct access to U.S. facilities such as TARP).

\section{Via the SLS, banks were allowed to swap their high-quality, but temporarily} illiquid securities for U.K. treasury bills. These extraordinary measures are now being dismantled. The treasury bills lent under the SLS are being gradually repaid, actually somewhat ahead of the planned schedule in order to avoid major repayment humps when the bonds mature. ${ }^{12}$

\section{Since the crisis, the BoE has instituted a permanent DWF for bilateral liquidity} support. The perceived risk of stigmatization of this facility remains an issue though. Banks avoid using extraordinary funding facilities, wishing not to be regarded as "being in need." Furthermore, the mission understands that the BoE and the FSA have encouraged firms to identify and to pre-position large amounts of collateral at the BoE in order to facilitate rapid draw down of funds in the DWF, if and when needed.

\section{In addition to the new DWF, the BoE also introduced a new permanent liquidity} facility in June 2010. This facility is intended to be available and useful both in normal times and during periods of stress. The new facility allows counterparties simultaneously to bid for funds against two distinct collateral sets - a "narrow" set, which comprises high-quality debt that is expected to remain liquid in all but the most exceptional circumstances, and a "wider" set, which comprises high-quality debt that is expected to remain liquid in most circumstances. The BoE regard this new facility with its innovative approach to collateral as a useful diagnostic tool, since increasing demand for liquidity against the wider pool of collateral could act as an indicator of growing market tension or funding difficulties.

45. The mission finds the U.K. crisis liquidity management appropriate. As in most other countries, the central bank acted flexibly and speedily in compensating for the supply shortfall from the normal markets. The central banks had to take larger risks than in normal circumstances, but this was necessary, given the circumstances. It is now important that there

\footnotetext{
12 Between April 2008 and January 2009, treasury bills with a face value of approximately GBP 185 billion were lent under scheme against illiquid collateral (mostly mortgage-backed securities).
} 
is a clear exit through which the banks return to their normal channels for funds and this process has already started in the United Kingdom. Stricter future regulatory requirements on bank liquidity will, hopefully, reduce the risk that banks need vast sums of extraordinary liquidity in times of market stress. Regarding ELA, during the crisis, the BoE provided ELA packages for specific problem institutions, with a view to reaching a longer-term solution for the recipient. Such institution-specific ELA packages were provided on a discretionary basis, consistent with the approach that the BoE has historically adopted. The BoE faces no legal restriction on its provision of ELA and it enjoys very broad, discretionary powers, which are legally robust. Although its powers in this regard are not circumscribed in statute, tripartite MoUs since 1998 have set out the framework through which ELA decisions would be expected to be made.

\section{Solvency support}

46. During the crisis, HMT engaged in a range of solvency support measures, including the recapitalization of two problem banks, and guarantees of both assets and liabilities (Asset Protection Scheme (APS) and senior bank debt guarantees). ${ }^{13}$ The mission notes that the U.K. authorities preferred to intervene early in the large and complex banks (for example RBS and HBOS) rather than use the SRR transfer tools (or rather their temporary predecessor under the Banking (Special Provisions) Act 2008 (BSPA).

\section{Solvency support measures made it possible for banks to fulfill regulatory}

requirements and avoid resolution. The mission does not object to this approach, which reflects that any kind of resolution of major financial groups would tend to include large operational, legal, and political challenges. An issue when applying ad hoc measures is to provide the right incentives both for the affected institution and for other market participants. For instance, shareholders and other junior debt holders should, as a rule, be written off before new capital is inserted. In cases of asset purchases/guarantees, it is important that the bank has a clear incentive to minimize the loss from the asset portfolio, and the APS Scheme Rules have apparently been designed to achieve this. Under the APS, the first loss risk and part of the secondary loss risk would fall on the bank and only after that would the guarantee be invoked. In the case of the RBS, the holdings of the original shareholders were substantially diluted. However, for certain reasons such as maintaining a market presence as a publicly-held firm and avoiding an outright nationalization, they were left a small portion of the bank. The mission understands the reasons for this solution although it represents a deviation from the ideal of ensuring that shareholders fully absorb losses. The solution also reflects the fact that ordinary resolution frameworks will often not be the optimal channel for dealing with very large and complex financial institutions.

\footnotetext{
${ }^{13}$ Lloyds Banking Group exited the APS in late 2009 and paid $£ 2.5$ billion levy for the protection received during its participation. The RBS continue to participate, paying an annual premium for the protection afforded under the scheme, whereby beyond the first $£ 60$ billion of losses on covered assets (which RBS would bear), losses would fall on the RBS and the government at a ratio of 1:9.
} 
48. The BA puts the potential for treasury support for banks on a firm statutory footing. In contrast to certain other jurisdictions (notably, the United States where the DoddFrank legislation explicitly prohibits public financial support), the U.K. framework implicitly acknowledges that in certain situations where systemic stability is threatened, public support for ailing banks may be unavoidable. Section 228 of the BA allows HMT to access the consolidated fund in order to provide financial assistance to banks quickly, if HMT considers that the need for funds is too urgent to permit arrangements to be made for the provision of money by parliament. Moreover, while the legislation anticipates that any such expenditure would be reported normally to parliament ex post, it permits HMT to delay or dispense with the report altogether if it considers it necessary to do so on public interest grounds.

\section{B. Banking Act 2009}

49. Pre-crisis, the resolution of U.K. banks had relied on general corporate insolvency law (codified largely in The Insolvency Act of 1986). However, the special features of banks, in particular the need to protect certain functions such as deposits, critical lending, and payment services, make it necessary to adopt specific resolution approaches for banks to ensure orderly procedures. Such approaches will also reduce the risk of systemic instability, e.g., through contagion. The lack of access to adequate tools for bank resolution will also occasionally lead to the authorities adopting unnecessarily expensive solutions to bank problems.

50. Lacking an appropriate legal framework for bank resolution, the United Kingdom responded to the failure of Northern Rock by adopting the BSPA in February 2008 as an emergency, temporary measure with a sunset clause of one year. The BSPA provided broad powers (based around forced changes to capital structure and mandatory transfers of property) to HMT used in the resolution of Northern Rock and other problem banks. Most (but not all) of the resolution powers introduced in the BSPA found a permanent home in the BA. The 2009 legislation placed the "private sector purchaser" and "TPO" stabilization options on a permanent footing and also introduced the option of a "bridge bank" resolution. On the whole, powers under the 2009 legislation are broader in scope than under its emergency predecessor, although certain powers conferred on HMT in the 2008 legislation (to vary the terms of contracts) are narrower in scope in the permanent 2009 legislation.

51. The BA establishes a permanent resolution framework built around a SRR for resolving banks, which includes a set of directed transfer powers (referred to as "stabilization powers" in BA) and a Bank Insolvency Procedure (BIP) for winding up insolvent banks in a manner protecting insured depositors. The BA, inter alia, sets out the trigger points for invoking the SRR, the objectives of the SRR, the various stabilization (i.e., transfer) options under the SRR, and the tools for achieving the desired results. The BA confers on the BoE and HMT powers to effect specific stabilization options in various situations and creates an obligation to consult with other authorities. Important secondary 
legislation sets out the standards for compensation to stakeholders affected by the resolution and also provides important creditor safeguards, preventing property transfer powers from being used in ways that could interfere with netting, security interests, and collateral rights for the mitigation of credit risk, and ensuring that in partial property transfers creditors are left no worse off than if the whole bank had been liquidated. To date, the resolution powers under the BA have only been used in one case; that of the building society Dunfermline.

\section{Useful features of the Banking Act 2009}

\section{The SRR provides a major step forward in U.K. legislation and has been in} many respects the model for the current proposed resolution framework in the EU. For example, a recent consultation paper from the COM (Financial Services) includes proposals which, with a few exceptions (albeit significant ones, such as the issue of pre-funding) are very similar to those already adopted by the United Kingdom. An important feature of a resolution framework is that it should provide transparency and predictability to all parties involved. The BA achieves this by defining a finite number of resolution options and tools. The BA also includes the objectives for resolution in specific cases, which will then guide which options and tools are to be used. The operation of the SRR and the roles of the different authorities are explained in Box 2.

\section{Box 2. Special Resolution Regime Summary}

When taking or contemplating any action under the SRR, the authorities must have regard to specified objectives. The objectives are not ranked according to any priority and their relative importance depends on the particular situation.

Objective 1: to protect and enhance the stability of the financial systems of the United Kingdom

Objective 2: to protect and enhance public confidence in the stability of the banking systems of the United Kingdom.

Objective 3: to protect depositors

Objective 4: to protect public funds

Objective 5: to avoid interfering with property rights in contravention of a convention right (within the meaning of the Human Rights Act 1998).

The SRR comprises three 'stabilization options' for resolving a troubled bank (i) transfer to a private sector purchaser; (ii) transfer to a bridge bank; and (iii) temporary public ownership. In this context, a 'bank' is effectively defined as an authorized deposit taking firm (per S2(1) of the Act). The stabilization options are effected by way of the "stabilization powers" which are the share and property transfer powers. The property transfer powers can be used to transfer only part of the property of the bank. The legislation also includes: (i) a bank insolvency procedure for winding up a bank ( in a manner that fully protects insured depositors) that is not resolved using a stabilization option; and (ii) a bank administration procedure to govern the insolvency of a residual entity that is left behind after the use of the property transfer powers where they have been exercise to transfer only part of the business of the BoE. 


\section{Box 2. Special Resolution Regime Summary (concluded)}

Before any stabilization power is used, the FSA must determine that both of the following 'general conditions' have been satisfied: condition 1 is that the bank is failing, or is likely to fail, to satisfy the threshold conditions for holding a banking license; and condition 2 is that having regard to timing and other relevant circumstances it is not reasonably likely that (ignoring the stabilization powers) action will be taken by or in respect of the bank that will enable the bank to satisfy the threshold conditions. The threshold conditions that are relevant to the FSA's determination are all of the conditions that an entity must fulfill in order to be authorized to carry out the regulated activity of deposit taking. While this covers a range of both qualitative and quantitative criteria, the most important conditions for SRR purposes would be prudential standards. Although the FSA makes the determination of the general conditions, the legislation requires it to consult with HMT and BoE.

If the general conditions are met, either the BoE (for transfer to a private sector purchaser or bridge bank) or HMT (for TPO) may use a stabilization option, subject to the relevant 'specific conditions'. Essentially, the specific conditions are public interest tests, where the relevant authority (whether the BoE or HMT) have to be satisfied that use of a stabilization option is necessary to counter a threat to U.K. financial stability or to protect the public interest. The threshold in the legislation is highest for TPO. The TPO is a 'last resort' option depending on necessity to counter a "serious threat" to financial stability. (In certain situations, the TPO power may also permit HMT to place a holding company in temporary public ownership). While the BoE and HMT have primary responsibility for determining if specific conditions are met, the legislation requires that they consult with each other and the FSA. If no specific conditions for using a stabilization option are met, the bank would be placed into the bank insolvency procedure with insured deposits being transferred to another bank, or FSCS paying out to insured depositors as rapidly as possible. It should be noted that even if the specific conditions are met for any of the stabilization options, the relevant authority need not take that action (i.e., the authority is not under a duty to do so, rather they have available the power to take the relevant action where the conditions are met).

Upon entry into the SRR, the BoE is the lead authority (except for TPO - for which HMT leads) conducting any sale of the bank to private parties or, as an intermediate measure, by establishing a bridge bank. After transfer powers have been used, the SRR also includes a bank administration process for the insolvency of the residual entity. An important feature of the bank administration process is a requirement for the residual institution in administration to provide continued services and facilities as needed to the recipient of the transferred business to enable it to operate effectively.

\section{The SRR seems to provide a fair balance between the protection of various} stakeholders on the one hand and the need to conduct speedy and orderly resolution on the other. ${ }^{14}$ The BA requires HMT to put in place compensation arrangements to ensure that persons affected by an exercise of the transfer powers are appropriately compensated for the interference in their property rights for the purposes of ensuring compliance with the requirements of Article 1 Protocol 1 of the European Convention on Human Rights. Where a partial property transfer power has been used, the framework provides compensation to stakeholders whose claims are left behind in the bank administration procedure on a "no-

\footnotetext{
${ }^{14}$ Special resolution measures are legally perfected via statutory instruments. The fact that the legislature effectively endorses every resolution action makes the action extremely robust and affords the relevant supervisory decision makers strong protection.
} 
worse-off-basis" generally implying that the stakeholder should not get a worse outcome than if the partial property transfer had not been affected and the whole bank had been liquidated under an insolvency procedure. ${ }^{15}$ Furthermore, secondary legislation under the BA establishes important creditor safeguards that prevent partial property transfers from being used in ways that could interfere with netting rights, security interests, clearing house default rules or payment flows in certain capital markets transactions (Banking Act 2009 (Restriction of Partial Property Transfers) Order 2009 (SI 2009/322)).

\section{Learning from the experience of earlier failures, the SRR contains a number of} provisions that facilitate an orderly procedure. Importantly, under the SRR, the authorities may temporarily suspend contractual termination rights that might otherwise have been triggered as a consequence of the use by the authorities of asset and capital transfer powers under the SRR. One notable exception to this however relates to financial derivatives contracts that contain netting clauses. Under relevant EU directives netting clauses are required to be given effect by member states "in accordance with their terms" and without qualification. As such, the suspension of termination powers under the BA does not currently extend to financial contracts subject to netting clauses or otherwise subject to the relevant EU directives. However, U.K. authorities may benefit from powers similar to those enjoyed by their U.S. counterparts, which do permit a 24-hour suspension of close-out rights relating to "qualified financial contracts" (QFCs), which include most derivatives), while the resolution authorities decide whether or not to transfer those contracts. If such a step is taken this should be underpinned by a robust cost and benefit analysis, taking into account the impacts on wider market participants. The EU is alert to this issue (which was also noted by the BIS' CBRG in its work on harmonization of bank resolution laws). It is likely that the forthcoming European legislative proposal on bank resolution will include provisions regarding the temporary suspension of early termination and close out netting rights pending a transfer when a resolution has been initiated. Should such a suspension of close out rights be included in the resolution regime, upon expiry of the suspension, full close-out and termination rights would be available for all financial contracts left in an insolvency procedure, but would not be available (other than for new, post-transfer defaults) for contracts transferred to a solvent bridge bank or private sector purchaser.

55. Under the SRR, the authorities are required to have regard to a Code of Practice that offers valuable guidance on the application of the regime. In many areas, the SRR itself requires different authorities to exercise discretion and judgment. The Code of Practice provides guidance to the resolution authorities, inter alia, on the choice between different

\footnotetext{
${ }^{15}$ The 'no creditor worse off' arrangements are established in secondary legislation. The relevant regulations require that where a resolution involving a partial transfer of property takes place, an independent valuer must be appointed. The valuer has to assess (i) what pre-transfer creditors would have received had transfer powers not been exercised; and (ii) what pre-transfer creditors actually receive. If the valuer determines there is a difference between the two sums assessed and a pre-transfer creditor is left 'worse off' the valuer may determine that compensation should be payable (and in what amount).
} 
resolution options and the determination as to whether general and specific conditions for the use of special resolution tools have been met.

\section{Scope and perimeter}

56. In its existing form, the SRR is applicable to commercial banks and, with some modifications to building societies that are authorized to accept deposits in the United Kingdom. BA provisions may also apply to credit unions, after a regulation by HMT to implement this provision in the legislation. The U.K. holding companies of banking groups are included to a limited extent (TPO is the only stabilization option to which holding companies may be subject). Also certain "continuity obligations" may be imposed on a residual bank or other banking group companies to continue to provide services and facilities to a solvent transferee (including a bridge bank) to which part or all of the business of a failing bank has been transferred. But the stabilization powers of the SRR are largely orientated at deposit-taking entities. As such, its usefulness in the resolution of a complex group may be limited (particularly international groups), unless the TPO power, which is meant to be a last resort under the SRR, is exercised. To a certain extent, efforts to resolve an entire group will always encounter certain practical and legal limitations (for example, restrictions on financial assistance can limit a cash-rich subsidiary's ability to recapitalize an ailing parent through direct purchases of equity). Nevertheless, it is important that the supervisory and resolution perimeters map each other as closely as possible. Given the SRR's limited scope at present, it is not clear that this is the case.

\section{Property transfer powers are a crucial component of the SRR but are only} useful if they can be used in relation to property that is within the perimeter of the SRR. If the property is located in an entity that is outside the perimeter of the SRR (either due to the nature of the entity or its location overseas) or if a contract that the authorities wished to transfer is governed by a foreign law, then the SRR's transfer powers alone may not perfect the transfer. ${ }^{16}$ This is not a weakness or deficiency of the U.K. regime but simply a problem that any domestic bank resolution regime will encounter in a cross-border context. These sorts of complicating factors bring into sharp relief the essential requirement for international collaboration if resolution frameworks that are useful for resolving international groups are to be realized..$^{17}$

\footnotetext{
${ }^{16}$ Transfer powers under the SRR may purport to affect overseas property. Within the EU, the EU Winding Up Directive for Banks may be of some limited assistance insofar as it ought to ensure the primacy of UK proceedings affecting the EU branches of UK banks. However, the SRR per se cannot perfect transfers of foreign property (within or outside the EU). The BA 09 addresses this issue at Section 39 by requiring transferor and transferee entities to take the necessary steps to ensure that transfers of foreign property become effective under the relevant foreign law.

${ }^{17}$ For a more detailed discussion by Fund staff on this question, see "Resolution of Cross-Border Banks - A Proposed Framework for Enhanced Coordination, IMF, June 2010."
} 
58. There is a debate on expanding the scope of the framework. In the public debate there are views that other potentially systemically important categories of institutions and systems should be included, such as investment banks, insurance companies, market infrastructure providers and maybe even money market funds and hedge funds if their failure could have systemic consequences. The rationale for including a broader set of entities would be that the framework is intended to protect against the disorderly winding-up of institutions any of whose failure might have systemic repercussions. For instance, the failures of a key settlement system or central counterparty could cause serious contagion.

\section{The mission agrees that the United Kingdom would benefit from having special} resolution tools that it could use in relation to certain nonbanks. However, since most of these other institutions and systems have operations and risks which are very different from those of the banks the existing options and tools under the SRR may not be applicable, or only partially so. That said, including some nonbanks under some kind of special resolution arrangements would likely have beneficial effects, for instance on market confidence. The mission recognizes that the United Kingdom is already taking steps to improve the corporate insolvency framework insofar as it applies to investment firms (Box 3).

\section{Financing bank resolution}

\section{The FSCS (the U.K.'s DGS) may participate in funding resolution under the}

SRR. The role of the scheme (discussed further at Section $\mathrm{C}$ below) is not limited to repayment in a liquidation. Indeed, it may contribute to the funding of SRR resolution transactions up to an amount not exceeding the cost to the FSCS, net of recoveries, of paying out to insured depositors in an insolvency. The FSCS is funded ex post and has access to HMT finance. Normally, the costs for resolution would be met by sales and other proceeds from the bank itself. However, if additional funds are needed, the FSCS has access to liquidity support via loans from the National Loan Fund. 


\section{Box 3. Investment Bank Insolvency and Client Assets}

Most crisis response measures in the United Kingdom revolved around deposit takers, and the BA itself is, of course, a particular response to the need for a special regime for resolving deposit takers. Nevertheless, the insolvency of Lehman Brothers' U.K. operation, Lehman Brothers International Europe (LBIE), has also exposed some of the problems of applying a standard corporate insolvency framework in winding down the affairs of a complex, internationally inter-connected investment firm. These issues are not unique to the United Kingdom. The collapse of Lehman Brothers has given rise to insolvency proceedings in jurisdictions across the globe. There has been no conclusion to these proceedings in any of the major jurisdictions, reflecting the complexity and interconnectedness of Lehman's international businesses. The slow pace of the insolvency proceedings has delayed the return of clients' property and the settlement of claims.

In the United Kingdom, legal disputes following the insolvency relating to the recovery of client money also exposed the firm's poor compliance with rules designed to safeguard client property.

Following a period of consultation during 2010, HMT has recently introduced new insolvency regulations for investment firms, while the FSA has taken some steps to improve the protection of client property held by brokers and custodians through changes to the Client Assets Sourcebook (CASS) contained in its handbook.

\section{Special Administration Regulations for Investment Firms}

The Special Administration Regulations (SARs) for investment firms were recently introduced to parliament under powers established in the BA. The SARs (which provide for a modified form of administration under Schedule B1 of the 1986 Insolvency Act) aim to speed up the administration process for investment firms. They aim to achieve this by clearly establishing the administrator's objectives and priorities, and by giving the FSA power to direct the administrator to carry out administration in accordance with a particular order of priorities. This may, for example, result in the administrator being directed to prioritize the return of client assets over the other objectives. This could be beneficial in a number of ways, including by relieving administrators of the need to regularly seek directions from the courts through the frequent court applications that have slowed down the LBIE administration.

Administrators under the Schedule B1 process do potentially face personal liability for actions taken in the administration process. This can contribute to caution on the part of the administrator and consequent procedural inefficiencies. It is hoped that by clarifying the administrator's objectives and priorities in investment-firm administration and by requiring those objectives to be pursued speedily and efficiently, the SARs may help to reduce the potential for legal challenges against administrators.

Under the SARs, an investment firm administrator is given the following three statutory objectives toward which he is required to work speedily and efficiently to (i) ensure the return of client assets as quickly as possible; (ii) ensure timely engagement with market infrastructure providers and the authorities; and (iii) either wind down or rescue the firm's business in the best interests of its creditors. The FSA, following consultation with HMT and the BoE, also has the power to direct the administrator to prioritize one of the objectives.

In working toward the first objective, the SARs allow for the setting of a bar date for submitting client property claims. The SARs also permit the administrator to allocate any shortfalls in client securities to all clients on a pro rata basis. These initiatives aim to achieve a faster and more certain outcome for all clients of a failed firm. The second statutory objective requires the administrator to work with market infrastructure providers in the smooth operation of their default rules. This objective is closely linked to another provision in the SARs which is designed to ensure that the insolvent investment firm continues to receive IT and communications supplies following its entry into administration. As stated above, the FSA can decide whether an administrator should seek to meet these objectives in a particular order of priority. 


\section{Box 3. Investment Bank Insolvency and Client Assets (concluded)}

In its first (December 2009) consultation on investment firm resolution, HMT consulted on the introduction of an operational reserve of cash/liquid assets that a firm in administration could use to retain key supplies and, above all, key operational personnel during the insolvency. The mission understands that discussions on whether to introduce such an operational reserve (and, indeed, whether to ring-fence it for specific postinsolvency purposes) are ongoing. The mission believes that the introduction of a ring-fenced operational reserve could be a useful addition to the U.K. framework for investment firm resolution.

\section{Lehman Brothers Client Money Litigation}

Under U.K. rules on client asset segregation for brokers and custodians, some complex firms have operated under a permitted 'alternative' approach in which client and house assets may be temporarily commingled intraday, before a once-daily account reconciliation exercise achieves proper segregation. Such an approach involves a risk that client property received after the firm's last segregation but before the firm enters insolvency will fail properly to be segregated.

Moreover, following the insolvency of LBIE, it appears that not only did such client property (received after the last segregation but before the entry into insolvency) fail to be segregated, but also that the firm itself may have failed properly to segregate much more client property over a prolonged period prior to its insolvency.

Furthermore, much of the client money that LBIE had successfully segregated had been deposited inside the group at a Lehman entity in Germany, which itself entered insolvency.

Due to LBIE's apparent poor segregation and the fact that even properly segregated client money remains trapped in an overseas insolvency process, the pool of available LBIE client money suffers from a substantial shortfall. Unsurprisingly, legal disputes have arisen between LBIE clients and the administrators surrounding the return of client money from LBIE. The main issues addressed in this important (and ongoing) litigation are: (i) whether identifiable 'client money' that is not properly segregated in a client account, but which may be in other accounts operated by the firm, is available for distribution to clients and so should 'top up' the pool; and (ii) whether the claimants on the client money available for distribution should include those clients whose money had not been properly segregated into the client account.

At first instance in January 2010, the high court ruled that only client money that had been properly segregated was available for distribution and that it was only available to those clients whose money had been properly segregated in the client accounts. In August 2010, the Court of Appeal disagreed with the high court's earlier judgment on these two key issues, and the litigation is now continuing on further appeal to the supreme court.

Whatever the merits of the legal arguments in play, from a purely practical standpoint, the mission observes that improved monitoring of firms' compliance with their segregation obligations is of paramount importance in avoiding such lengthy and costly processes for the recovery of client property. It is striking that over two years since LBIE's insolvency, client money has yet to be returned. If clients are to have confidence in brokers and custodians, it is essential that firms which hold client property on trust are held to an extremely high standard and are subject to rigorous and regular supervisory scrutiny. The mission also recognizes that, cognizant of this imperative, the FSA has now taken some steps to improve oversight of compliance with the client property rules and is likely to undertake a more comprehensive review of CASS once the ongoing litigation surrounding LBIE has come to an end.

\section{Discussions are currently ongoing within the EU on the merits of general bank} resolution funds, funded ex ante via industry contributions. The commission has noted that while some DGS (like the United Kingdom's) already play an enhanced role in 
resolution (through funding deposit transfers, etc.) general resolution funds could provide resolution financing above the limits at which DGS participation would be capped. Views amongst member states on pre-funded, general resolution funds appear to vary. Some are opposed, perceiving increased moral hazard (as bank stakeholders might regard such funds as an implicit guarantee that they would be rescued in all cases, so they might change their behavior in ways contrary to the public interest) while observing that amounts raised could be insufficient in any event. Opponents also note that fiscal costs cannot be completely eliminated (much of a pre-fund would sit as government paper, whose large-scale liquidation at the point of requiring the funds could nudge up rates). Conversely, proponents attach value to the political signaling effect of raising general resolution funds, ex ante and via industry contributions, and some countries have begun to build up such funds. EU discussions on this topic are far from finalized, however. Currently, the United Kingdom does not have a general bank resolution fund and the bank levy, which has recently come into force, is a purely fiscal measure and is not intended specifically to fund public costs for resolving banks.

\section{The need for early intervention}

\section{All frameworks for crisis management and bank resolution must strike an} appropriate balance between rules and judgment. Clear rules are important to provide transparency and to avoid moral hazard. Allowing the use of judgment is important since bank distress situations differ from one another and hence the optimal solutions will always vary according to the situation. Nevertheless, introducing too large an element of subjectivity and discretion might increase the danger of mistiming the appropriate moment to initiate resolution. A perceived "no-failure attitude" from the authorities creates incentives to delay drastic actions, such as bank resolution.

63. As a first important step, the "no-failure" perception must be altered. The authorities have expressed their will to do so and have shown a stricter approach when later dealing with a number of potential problem banks. A change in perception will be achieved through a combination of external communication and practical examples, that is, by letting banks actually fail. Moreover, it is clear from both the BA and the Code of Practice issued under it, that where bank problems arise idiosyncratically as opposed to during a systemic crisis, it is expected that if the failure of the bank in question is not deemed likely to have adverse systemic consequences, it would be allowed to enter insolvency and would be wound up under the Bank Insolvency Procedure contained in Part 2 of the BA rather than resolved using any of the stabilization options.

\section{The 'general conditions' for resolution would likely only be met at quite a late} stage. As part of its assessment of the general conditions for triggering the SRR, the FSA must be satisfied that it is not reasonably likely that (ignoring the SRR tools) action will be taken by or in respect of the bank that will enable to bank to satisfy the threshold conditions. This 'Condition 2' (Section 7(3) of BA) is formulated in a way that makes it unlikely that the FSA could 'pull the trigger' at a very early stage. The Code of Practice issued under the 
SRR itself also makes clear that the intention of Section 7 is that a bank "could only enter the SRR at a point where it is clear that there is no realistic prospect that it will be able to continue as an authorized deposit taker."

65. This approach has pros and cons. On the one hand, bank management knows that entry into the SRR effectively implies the loss of their bank. Awareness of the drastic consequences of entry into the SRR may improve the chances of restoring a bank to viability outside the regime. The SRR clearly provides certainty. If a bank cannot be rescued by the existing stakeholders, the BA ensures that it will be either sold, resolved, or liquidated, and with minimum disruption to the wider market. The SRR avoids the uncertainty, contagion, and instability that could flow from keeping a comatose institution operating in the system. On the other hand, the fact that SRR is likely to be triggered only at a very late stage means that value may be $\operatorname{lost}^{18}$ in situations where it has not been possible to find a private sector solution outside the SRR. There is also the risk that the later the 'trigger' is pulled through satisfaction of the 'general conditions', the fewer may be the realistic options available to BoE, potentially limiting their choice of stabilization options.

\section{Greater emphasis on pre-resolution, supervisory intervention powers may} therefore be beneficial. It is important that the FSA, and through it the other relevant authorities receive early warning of potential problem banks as long in advance of reaching the threshold conditions as possible and ensure where possible that remedial action is taken by the firm itself. The mission understands that the FSA plans to introduce such an early warning system, which would identify the situation of banks in a step-wise assessment system. As a certain step is reached — defined through a set of criteria-FSA may react by taking various measures. That said, the system is not expected to deprive the FSA of the opportunity to use its discretion. Such a system would be useful both for assisting to guide the allocation and extent of supervision and supervisory intervention in normal times and as a pre-warning when a specific bank moves closer to the trigger point for resolution. The FSA should also develop integrated processes to ensure that other members of the tripartite and the FSCS, when appropriate, receive early information on banks' movements along the stepladder, in particular for sudden or sharp downward movements.

67. It is important that the FSA make full use of available powers (and that there is an expectation that they will be used) to intervene early, being able to choose from a sufficiently wide range of remedial measures when bank weaknesses have been identified. There must also be processes to ensure that orders for corrective measures are monitored and that clear and early time limits for implementation are set. Many supervisory authorities globally have dedicated units and/or reporting systems for ensuring an effective

\footnotetext{
${ }^{18}$ For instance, through increased losses after the management tries to "save the bank" via assuming higher risks.
} 
monitoring of banks' taking the prescribed measures. These units/systems cooperate closely with the supervisory teams responsible for the relevant institution. ${ }^{19}$

\section{Cross-border issues}

68. There are clear limitations to the effective use of the SRR tools when assets are held under other jurisdictions than the United Kingdom. For instance, transfers of assets from overseas in order to be included in a U.K. resolution cannot be achieved with certainty. Indeed, foreign authorities may wish to "ring fence" assets held in their countries to minimize their potential losses, should the bank fail. The U.K. authorities acknowledge these limitations and work with international committees, such as the FSB and BCBS, with a view to harmonize international resolution approaches as far as possible.

\section{The IMF mission agrees with the U.K. approach to work to seek a globally}

harmonized approach. Since this is likely an international project for the medium or long term, certain things can be done in advance to facilitate the use of resolution techniques (such as asset transfers) across borders. There could, for instance, be a mapping of relevant legislation and identification of potential legal issues among the countries in a supervisory college. There could also be agreements not to take unilateral decisions, such as ring-fencing, before having consulted with the other relevant home- or host-country authorities though in some jurisdictions any ability to agree not to act unilaterally may be constrained by current applicable law that may effectively require unilateral action in certain circumstances.

\section{Financial Services Compensation Scheme}

70. The FSCS is an operationally independent body accountable to the FSA. The organization manages a protection scheme with five sub-schemes for different categories of customers, one of those being insured depositors in deposit-taking institutions.

71. It is an ex-post funded scheme so when the scheme has incurred costs, the membership, which consists of all institutions having insured deposits, will be required to cover the costs on a pro rata basis (respective share of protected deposits up to the compensation limit per individual depositor per authorized bank). The principal costs for the pay-outs during 2008 have not yet been allocated, awaiting the liquidation proceedings, which will decide the final net costs to the FSCS. In the meantime, the Treasury has provided the FSCS with a loan, the principal of which will be repaid from 2012 onwards (interest on

\footnotetext{
${ }^{19}$ It is necessary to implement penal and remedial supervisory measures swiftly and adequately. That said, when selecting specific measures and when implementing them, the FSA must take into account the risk that if /when the measures get publicly known there might be unwarranted side-effects to the bank from various counterparts. This could exacerbate the bank's problems. This risk is not a reason for not acting, nor a reason for (in most cases) keeping measures secret. Rather, it stresses the importance of acting in a way and at a time which strengthens the bank also in the eyes of the external stakeholders.
} 
the loans is currently being repaid). In winding up procedures, when the FSCS is subrogated to transferred depositors, the FSCS ranks pari passu with other unsecured creditors.

72. During consultations on the BA, the possibility of introducing a depositor preference was mooted but, for the time being, like some other European member states, the United Kingdom does not give depositors a preferential ranking in insolvency. It should be noted, however, that at least as far as the individual insured depositor is concerned (if not the FSCS who must claim pari passu with other unsecured creditors in the insolvency of the residual, failed bank ${ }^{20}$ ), SRR transfer tools and powers can - and are expected to be - used in ways that achieve a practically similar outcome to depositor preference. Moreover, international progress on putting in place 'bail-in' arrangements could result in a de facto depositor preference that may raise the question of formalizing, such preference de iure.

\section{FSCS funds may be used for:}

- $\quad$ Pay-out to depositors in an application of the bank insolvency procedure.

- $\quad$ Financing the transfer of insured deposits to another institution under the bank insolvency procedure. ${ }^{21}$

- Contributing to a non-payout resolution of a failed bank using the stabilization powers. In this case, the FSCS will only act upon the order of HMT and the FSCS; contribution must be no more costly to the FSCS, net of recoveries, than if the payout/liquidation option had been used.

\section{In a pay-out situation the FSCS has unlimited access to borrow from the} National Loan Fund. As a normal procedure, followed in a number of cases during the crisis, the FSA will alert the FSCS on potential problem institutions. When appropriate, the FSCS will contact the institution to make sure that a pay-out can be handled quickly. For instance, all banks are now required to have account systems allowing a "single depositor view", i.e., that all deposits pertaining to a depositor can be easily summed up and presented in a list. FSCS expects a pay-out period of maximum 7 days for most deposit accounts and up to 20 days for more complex claims. It would be desirable for the FSCS to pay out all eligible claims within a target of 7 days.

\section{The potential for conflict, such as in the case of the Icelandic banks, in pay-outs to cross-border banks has been reduced since EU legislation no longer allows the}

\footnotetext{
${ }^{20}$ This potentially implies additional cost to the FSCS (and, possibly, HMT in the short term) that depositor preference rules could help to mitigate.

${ }^{21}$ The cost to the FSCS of exercising this option must not be higher, net of recoveries, than if the payout/liquidation option had been used.
} 
"topping-up", when a country that covers deposits to a higher level than the home country, allows depositors in the host country institution to pay a premium and thereby get access to the higher cover ratio. The EU is presently discussing further changes to deposit guarantee schemes with a view to harmonize them.

\section{From a crisis management point-of-view, the IMF mission regard the}

U.K. deposit guarantee system to be well advanced. In particular, the possibility of using the scheme not only in a simple pay out function, but also to facilitate other resolutions will make it more useful and it will also hopefully imply a more efficient use of funds. The FSCS also seems prepared to act quickly, provided that the FSA informs it at an early stage, which so far seems to be the case. As observed elsewhere in this note, this process can be underpinned by identifying some "trigger points," in addition to the use of supervisory discretion, of which the FSA is obliged to inform the FSCS.

\section{Conclusions}

77. If there has been any silver lining to the United Kingdom's experience of the clouds of financial crisis, it is that it has now developed a bank resolution framework that fills a significant gap in its pre-crisis framework. Moreover, the mission is reassured that the authorities (notably, through their liaison with the Banking Liaison Panel) ${ }^{22}$ see the United Kingdom's crisis management framework as a 'living being' that can be continually reviewed and improved. The mission also notes the United Kingdom's contribution to important and ongoing international debates on questions relating to the resolution of LCFIs and SIFIs.

\footnotetext{
${ }^{22}$ The Banking Liaison Panel combines industry and government representatives to advise HMT on, inter alia, the impact of the SRR on financial markets.
} 